\title{
Significance of public health ethics in the time of Covid-19
}

\section{LAKSHMI LINGAM}

Arima Mishra, Kalyani Subbiah (Editors), Ethics in public health practice in India, Singapore: Springer Nature Singapore Pte Ltd, 2018. 189 pgs, Kindle price INR 8,221.50, ISBN 978-981-13-2449-9.

This book is an important contribution to the understanding of public health ethics practice and has enormous relevance in the current times of Covid-19. Its contents will alert us to the everyday forms of violation of the rights of ordinary people while addressing various health issues that affect individuals at scale. For example, marking houses, individuals and families quarantined or found positive to Covid-19 testing; sharing the personal information and addresses widely through websites and social media; shaming and trolling individuals, particularly celebrities for testing positive; stigmatising individuals in quarantine; and labelling individuals and communities routinely as — "Dubai returnee,","Tablighi Jamaat attendee" etc. Spraying of disinfectant on migrants, using physical violence on individuals found in public places outside their homes; or communities attacking health personnel visiting their homes for testing or imparting information; private vigilantism collectively signal egregious legal violations, gross ethics and rights violations at various levels.

In such a health emergency as the current one, the State prioritising its response as a law and order problem undermines the recognition of the rights to privacy, confidentiality, access to equitable healthcare, nondiscrimination, non-maleficence, right to life and livelihoods of all the people, by duty bearers. Ethics and rights foreground the relationship of the citizen with the state and compromising these undermines the social contract between these two.

The preface to the book by John D H Porter sets the tone by pointing out that "Public health is not about the market or about profit, it is about life, individuals, communities and well-being" (p.vii). Through an introductory chapter that reviews the "why of public health ethics" as opposed to "bio-ethics" that cover clinical research and research with human subjects, the editors,

Author: Lakshmi Lingam (lakshmi.lingam@gmail.com), Professor, School of Media and Cultural Studies, Tata Institute of Social Sciences, VN Purav Marg, Deonar, Mumbai 400 088, INDIA.

To cite: Lingam L. Significance of public health ethics in the time of Covid-19. Indian J Med Ethics. 2020 Jul-Sep; 5(3) NS: 249-50. DOI: 10.20529/ IJME.2020.060

Published online on May 18,2020

Manuscript Editor: Sanjay A Pai

(c) Indian Journal of Medical Ethics 2020
Arima Mishra and Kalyani Subbiah unpack what is "public" of public health. Within a context of social inequalities, public health ethics has a special significance to ensure equity in access to healthcare, non-discrimination in service delivery and commitment to rights and justice for all people. Public health ethics plays the role of conscience keeper raising serious questions on behalf of the global poor, advocating for health rights, access and equity. The introduction lays the ground for understanding the relevance of public health ethics within policymaking, implementation/practice, education, training and research.

The second chapter by Edward Premdas Pinto discusses the conflicts and contestations in the rights and ethics discourses. This chapter points to the neo-liberal ascent in policymaking that has given an impetus to the privatisation of healthcare and a steady withdrawal of the state from investments in the public health sector, thus compromising the deep-seated rights commitments of the state to its people through the Constitution. The core issue of this chapter is evident in what we have been witnessing in recent times. The irony of the underfunded, neglected public healthcare systems confronting Covid-19, testifies to the significant role of the state which cannot be replaced by corporate capitalism and markets.

"Off the shelf" thinking in terms of health programme design and preconceived understanding of impacts measured through programme evaluation, are examined in a chapter by Suraj Jacob through a detailed case study of a government nutrition programme. The author points out that programmes are often dictated by the economics of programme delivery and bio-medical pre-requisites that need to be adhered to in the programme. However, in the process the significance of the socio-economic positionality and structural disadvantages of individuals is ignored, often leading to a "framework of blame" of the populations that the programme has set out to benefit, thus compromising the very objectives of the programme. The issue of "equipoise" in randomised controlled trials, the straitjacketed ways of programme design that disregard the multifaceted realities, and the poor integration of evaluation results in re-orienting public policy have been addressed by this chapter.

Execution of major national health programmes is fraught with several challenges to effectiveness, efficiency and achievement of the stated goals of the programme. Authors Babu and Yamuna in Chapter 4, attempt to examine the applicability of a framework of ethical principles like respect for persons, beneficence and justice which are often applied in the case of research to public health programmes like the Revised National Tuberculosis Control Programme, the Human Papilloma Virus Vaccination project and other disease eradication programmes. The authors highlight serious 
gaps on most of these counts and emphasise the need for policymakers to adhere to the spirit of the Belmont report in devising public health programmes and implementing them.

Within the non-health sector, the impact of polluting industries, transportation, construction, mining or pesticides and fertilisers on human and environmental health is increasingly coming to light. In Chapter 5 of this book, Adithya Pradyumna and Jayakumar Chelaton trace the health consequences of air spraying Endosulfan for cashew plantations in Kasaragod, Kerala. This chapter deems as an ethical violation the introduction of hazardous chemicals without consideration of its implications for the environment, people and future generations. The chapter highlights the need to introduce a health impact assessment at par with environmental and social impact assessment of development projects.

Surekha Garimella and Lakshmi Josyula share a self-reflexive and insightful paper of their research into health systems using qualitative research methodology in Chapter 6. The paper provides insights into State permissions, gatekeeping by officials, non-recognition of the consent of junior functionaries and low opinion of evidence produced by qualitative research. The oft understood relationship of the researcher and researched from the prism of a power hierarchy within ethical discourse is problematised by these authors.

Chapter 7 by Vijayaprasad Gopichandran and Varalakshmi Elango deals with the ethics of data generated through surveillance, big data analytics and digital epidemiology. In contemporary times, there is much discussion around the Arogya Setu app and Aadhar linkage to health insurance and the ensuing risk of privacy and confidentiality breaches by the State. The authors suggest the need to institute an Ethics Review Committee to provide oversight for public health interventions and data protection mechanisms to secure the resultant digital data.

The ethical challenges intrinsic to the Assisted Reproductive Technologies industry, the location of women within the surrogacy markets, the trade in biological materials with poor regulation of each aspect are dealt with by Sarojini Nadimpally and Deepa Venkatachalam in Chapter 8. Chapters 9 and 10 cover the attempts at introducing a Public health ethics curriculum in a progressively-oriented medical college in Bangalore, and in the newly set up innovative Azim Premji University in Bangalore, respectively. Both these papers provide insights into the value and significance of such courses in building a cadre of ethically committed professionals.

To add to the strength of the book, the authors could have devoted space to discussion of the dominant philosophical positions (utilitarianism, liberalism, communitarianism and feminism) which have been alluded to on page 9 and their application to the themes explored in the book. This book is an important contribution to the emerging field of public health ethics in India with case studies, field experiences, research and reflections of public health researchers, teachers, trainers, practitioners and activists.

\section{Consonances and dissonances: ancient Ayurveda and contemporary} Ayurvedic clinical practice

\section{JOSYULA K LAKSHMI}

\section{Sanjeev Rastogi, Editor, Translational Ayurveda, Springer Singapore, 2019, e-book ISBN 978-981-13-2062-0, 212 pages, Euros 96,29.}

The book Translational Ayurveda, authored by academics in Ayurvedic practice and research, lays out the terrain of the current practice of Ayurveda, setting it in the administrative and policy landscape of India as well as some other parts of the world, and describing the consonances and dissonances between the principles delineated in the classical texts, and

Author: Josyula K Lakshmi (jlakshmi@georgeinstitute.org.in), The George Institute for Global Health, Punjagutta, Hyderabad, 500082 INDIA; University of New South Wales, Sydney, AUSTRALIA.

To cite: Lakshmi JK. Consonances and dissonances: ancient Ayurveda and contemporary Ayurvedic clinical practice. Indian J Med Ethics. 2020 Jul-Sep; 5(3) NS: 250-2. DOI: 10.20529/IJME.2020.082.

Manuscript Editor: Sanjay A Pai

(c) Indian Journal of Medical Ethics 2020 contemporary teaching and practice. The book is divided into sections to (i) present the basic tenets of Ayurveda; (ii) describe the pharmaceutical formulations and modes of administration, and trace their history; (iii) elaborate the emphasis on protecting and promoting health, and preventing disease in Ayurveda; and (iv) detail clinical practice and research in particular disease conditions, viz cancer, diabetes mellitus, and skin ailments, and the role of sleep as a diagnostic and therapeutic marker. In addition to being a guide to the nonpractitioner about the translation of classical Ayurveda to clinical and health-promoting practice in today's world, this book highlights the roles of funding, policy support, and administration in the development of the field.

\section{Is Ayurveda practised as taught? Is it taught as it ought to be?}

A question that the authors engage with is whether the core of Ayurveda's approach to health, the celebrated holistic 